\title{
Monocitosis en Pediatría
}

DRES. JOSE MANUEL DONOSO,* HECTOR RIVEROS, * TAREK SAAD * Y HERNAN TABOADA.*

Nos llamó la atención encontrar con cierta frecuencia cifras de monocitos de sobre $15 \%$ en hemogramas de lactantes hospitalizados. Revisando los textos de Pediatría no encontramos una explicación satisfactoria. Así por ejemplo en la edición de 1968 del libro de Barnett ${ }^{1}$ se dice que los monocitos derivan del sistema reticuloendotelial (?), constituyen el 5 a $10 \%$ de los leucocitos circulantes y aumentan en la recuperación de infecciones agudas, en la TBC activa, endocarditis bacteriana sub-aguda, Enfermedad de Hodgkin y algunas lipoidosis (Niemann-Pick). En el tratado de Nélson de $1975^{2}$ se lee casi textualmente del monocito: "célula fagocítica grande, caracterizada por un núcleo grande y lobulado y citoplasma gris abundante con granulos finos azurofilos. Normalmente constituyen del 1 a $5 \%$ de los leucocitos circulantes, pero aumentan en enfermedades como la tuberculosis, micosis sistémicas, endocarditis bacteriana y ciertas infecciones a protozcos". Por su parte Cooke ${ }^{3}$ acota en 1968 "que no hay información definida del origen, vida media, y regulación del monocito; que su identidad con el histiocito tisular no ha sido probada, pese a que tiene estructura y funciones similares. Los macrófagos tisulare sdel SRE, los que se transción, entre las 8 y 12 hrs. de lesionado un tejido. Su relación con la formación de anticuerpos no es clara". En su tratado de Hematología pediátrica (1972) , Smith ${ }^{4}$ relaciona a los monocitos con los macrófagos tisulares del SRE, en los que se transformarían en el peritoneo y tejidos, acotando que ambos tienen un rol importante en la defensa antiviral. Su lista de las causas de monocitosis es un poco más larga: recuperación de infecciones agudas, reabsorción de neumonías, fiebre reumática aguda, TBC activa, Sarcoidosis, Hodgkin, infecciones a protozoos (malaria), recuperaciôn

\footnotetext{
- Servicio de Pediatria, Hospital Josefina Martínez de Ferrari, Departamento de Pediatría. Universidad Católica de Chile.
}

de agranulocitosis, lipoidosis, mononucleosis infecciosa y adenitis mesentérica.

No satisfechos con estas explicaciones iniciamos una revisión más amplia de la literatura que resumimos con el título de "El Sistema Mononuclear Fagocitario" en esta misma revista", y decidimos reunir y estudiar todos los casos que tuvieran más de $15 \%$ de monocitos en el hemograma, lo que constituye el motivo de la presente publicación.

\section{Material y Método:}

Entre Marzo y Noviembre de 1974 ingresamos a un protocolo de estudio todos los niños hospitalizados que tuvieran en el hemograma más de $15 \%$ de monocitos. E1 frotis fue revisado personalmente por uno de nosotros (H.T.), catalogándose como monocitos sólo las células sanguineas que por su tamaño y configuración nuclear y citoplasmática no of recieran ninguna duda al respecto. Todas las células de aspecto monocitoide "atípico" se englobaron bajo la denominación de "linfocitos atípicos" (linfo-monocitos, linfocitos medianos hiperbasófilos monocitoides, linfocitos hiperbasófilos grandes tipo Downey, linfoplasmocitos, etc.). Estamos conscientes que entre estas células debieron figurar muchos monocitos jóvenes, en especial si tenemos presente que en estudios recientes ${ }^{6}$ se ha estimado que normal mente existen en la sangre un número casi igual al de los monocitos circulantes que se catalogan como linfocitos por su aspecto morfológico. Si esto es así debemos asumir que la cifra "normal" de monocitos circulantes, que oscilaría entre 1 y $10 \%$, debe duplicarse para tener la cifra "normal real". Estamos conscientes también que al elegir como condición de ingreso al estudio un valor relativo superior al $15 \%$ de monocitos, de- 
jamos fuera muchos casos de monocitosis absolutas, precisamente aquellas que por cursar con leucocitosis pueden tener mayor significado patológico.

Bajo estas premisas, de 1.317 hemogramas seleccionamos 57 casos $(4,3 \%)$ con más de $15 \%$ de monocitos. A este grupo revisamos cuidadosamente los antecedentes clínicos, exámenes de laboratorio, radiológicos y en algunos anatomo-patológicos para establecer el diagnóstico de la enfermedad causal y el momento de la evolución en que apareció la monocitosis. Dado que no dispusimos de estudios virológicos catalogamos como de origen viral aquellos casos que en el comienzo de su enfermedad no presentaron alteraciones cuanti- o -cualitativas de los polimorfonucleares neutrófilos en tanto si tenían linfocitos hiperbasófilos. A esto se agregó el criadro clínico, y en los casos de bronconeumonías el estudio radiográfico con sombras difusas, tenues, hiliofugales o claramente de tipo interticial. Como convalescientes se catalogaron aquellos casos en que la monocitosis apareció después de 7 a 10 días del inicio de la enfermedad aguda, siempre que ésta no fuera un cuadro séptico no tratado en forma adecuada.

Como valores normales de leucocitos para pacientes pediátricos entre 4 semanas y 2 años damos la siguiente tabla de referencia ${ }^{7}$ en cifras $a b$ solutas $\left(\mathrm{x} \mathrm{mm}^{3}\right)$ :

\begin{tabular}{lccc}
\hline & Mínimo & Promedio & Máximo \\
Leucocitos & 5.000 & 11.000 & 18.000 \\
$\begin{array}{l}\text { Neutrofilos } \\
(30 \text { a } 35 \%)\end{array}$ & 1.000 & 3.800 & 9.000 \\
$\begin{array}{l}\text { Linfocitos } \\
(40 \text { a } 60 \%)\end{array}$ & 2.500 & 7.000 & 13.000 \\
$\begin{array}{l}\text { Monocitos } \\
(1 \text { a } 10 \%)\end{array}$ & 50 & 600 & 1.000 \\
$\begin{array}{l}\text { Eosinofilos } \\
(1 \text { a } 3 \%)\end{array}$ & 40 & 300 & 800 \\
\hline
\end{tabular}

\section{Resultados:}

En la tabla № 1 se muestra la distribución por edad de los casos de monocitosis. Se puede apreciar una franca acumulación en los menores de 9 meses, en que se presenta el $85 \%$ de los casos (47 casos). De ellos el 65\% (37 casos) corresponde a menores de 6 meses. Al año de edad ya se ha presentado el $90 \%$ de las monocitosis (51 casos).

De estos lactantes 12 eran eutróficos, 18 desnutridos de 1er. grado ( $<10$ a $25 \%$ del peso) . 13 de $2^{\circ}$ grado $(<25$ a $40 \%)$ y 8 de 3 .er grado
TABLA 1

MONOCITOSIS - DISTRIBUCION POR EDAD

\begin{tabular}{lccc}
\hline Edad & $\begin{array}{c}\text { Número de } \\
\text { hemogramas }\end{array}$ & $\begin{array}{c}\text { Más de 15\% } \\
\text { de monocitos }\end{array}$ & $\%$ \\
\hline$<3$ meses & 244 & 17 & 6,9 \\
3 a $5 \% "$ & 364 & 20 & 5,5 \\
6 a $8 \%$ & 241 & 10 & 4,1 \\
9 a $11 "$ & 104 & 4 & 3,8 \\
1 a 12 año; & 364 & 6 & 1,6 \\
\hline TOTALES & 1.317 & 57 & 4,3 \\
\hline
\end{tabular}

TABLA No 2

MONOCITOSIS SOBRE $15 \%$

DISTRIBUCION NOSOLOGICA ESTACIONAL

\begin{tabular}{lcccc}
\hline Infecciones & No casos & III a V & VI a VIII & IX - XI \\
\hline Respiratorias & 28 & 4 & 20 & 4 \\
Enterales & 11 & 4 & 2 & 5 \\
Sapsis & 9 & 4 & 3 & 2 \\
Meningitis & 3 & 2 & 1 & - \\
Neoplasias & 3 & - & - & 3 \\
Otras & 3 & - & 2 & 1 \\
\hline T O T A L E & 57 & 14 & 28 & 15 \\
\hline
\end{tabular}

(Déficit $>40 \%$ del peso). Anemia intensa (Hto $<20 \%$ ) sólo presentaron 2 casos de sindrome hemolítico-urémico, moderada (Hto. entre 20$25 \%$ ) sólo 1 caso (sindrome de Reye), leve (Hto $26-30 \%$ ) 4 casos. Trombopenia franca se constató en 3 casos ( 2 sindromes hemolítico urémico y una sepsis).

En la tabla No 2 se resume la distribución estacional de los 57 casos de monocitosis.

Se observa una franca acumulación de casos en los meses de invierno (Junio-Agosto) hecho que ha sido observado incluso en adultos en el hemisferio Norte (Enero-Marzo), atribuyéndose a factores "ambientales". Como era de esperar, en los meses de invierno predominan las infecciones respiratorias, y de ellas por lo menos 15 son claramente de origen viral ( 7 bronquitis, 5 neumonitis, 2 bronquiolitis, 1 gripe). Incluso de las 3 sepsis, 2 cursaron con bronconeumonía y 10 mismo es válido para la meningitis, de etiología neumocócica. En otoño y primavera en cambio aumentan las infecciones enterales (Diarreas agudas con deshidratación, enterocolitis y 1 tifoidea), y de las 6 sepsis, 5 eran claramente de origen 
$\begin{array}{lll}\text { TABLA } & \mathbf{N} & 3\end{array}$

Monocitosis - Distribución por Edad y Causa

\begin{tabular}{|c|c|c|c|c|c|}
\hline & $6 \mathrm{~ms}$. & 6 a $11 \mathrm{~ms}$ & 1 a 12 años & No casos & $\%$ \\
\hline Infecciones Virales Agudas & 19 & 7 & 1 & 27 & 47 \\
\hline Infecciones Bacteriana Ag. & 11 & 3 & 1 & 15 & 26 \\
\hline Convalecencia & 7 & 4 & 1 & 12 & 21 \\
\hline Neoplasias & - & - & 3 & 3 & 5 \\
\hline TOTA L E S & 37 & 14 & 6 & 57 & 99 \\
\hline
\end{tabular}

enteral (2 por citrobacter, 1 por Proteus, 1 por Pseudomona, 1 por Klebsiella). Las meningitis fueron por Hemofilus y una de ellas falleció, comprobándose en la necropsia un estado séptico generalizado. En el rubro "otras", figuran dos sindromes hemolítico-urémicos y un sindrome de Reyé. entidades de etiopatogenia discutida pero que al parecer tienen un origen viral ${ }^{9}{ }^{10}$. Las 3 neoplasias -leucemia monocítica-Hodgkin y Tumor de Wilms- se acumulan en primavera. En la última de ellas la monocitosis relativa apareció con el tratamiento radioterápico, debiendo interpretarse como regresión de una granulocitopenia.

En la tabla № 3 se resume la distribución por edad y causa de los monocitosis. Cerca del 50\% de los casos correspondió a infecciones virales agudas. Ya se dijo en el análisis de la tabla $\mathrm{N}^{\circ} 2$ que las infecciones virales correspondieron en su gran mayoría a cuadros respiratorios ( 8 bronquitis, 2 bronquiolitis, 3 neumonitis interticial y 6 bronconeumonías, 1 gripe y 1 caso de sarampión). Se agregan aquí 4 casos de diarrea aguda y/o enterocolitis catalogados como de origen viral por presentar alteraciones en los linfocitos; y uno de los sindromes hemolítico-urémicos precedido de un cuadro diarreico como es lo habitual. Nuevamente se destaca que la gran mayoría de los casos se presentó en menores de 1 año, en especial en el primer semestre. Sólo un caso aparece después, correspondiendo a un niño de 2 años 6 meses que falleció al $2^{\circ}$ día de hospitalziación, comprobándose en anatomía patológica una sepsis viral con neumonitis interticial difusa, miocarditis focal con necrosis de fibras miocárdicas y encefalitis aguda con infiltrados perivasculares de mononucleares.

Las infecciones bacterianas agudas con $15 \mathrm{ca}$ sos representan un $26 \%$. Se presentaron casi todos (1 excepción) en menores de 9 meses. Los 6 casos menores de 3 meses fueron todos de sepsis, 3 de ellos con la localización pulmonar predominante. Se agregan otras 3 sepsis entre los 3 y 5 meses (1 con meningitis a Hemophilus) y una en el grupo de 6 a 8 meses, totalizando así 10 de los 15 casos de infecciones bacterianas agudas. Los restantes corresponden a 3 enterocolitis y una meningitis y una bronconeumonía.

Entre los convalescientes $(12$ casos $=21 \%)$ figuran prácticamente los mismos cuadros virales o bacterianos (aunque solamente 1 caso de sepsis con meningitis a pseudomona), pero predominando los bacterianos en proporción de 8 a 4 . Destacamos aquí 2 neumonitis crónicas (de más de 3 meses de evolución), un sindrome de Reyé (tenía al ingreso $11 \%$ de monocitos y $1.298 \times \mathrm{mm}^{3}$ ) un sindrome hemolítico urémico que sobrevivió y una tifoidea de 4 semanas sin tratamiento en una niña de 9 años.

Las neoplasias se presentaron a los 3 años 6 meses (T. de Wilms), 7 años (Hodgkin) y 12 años (Leucemia monocítica) respectivamente. Podemos agregar aquí, aunque fuera del estudio, un caso de Histiocitosis $x$ difusa (Enfermedad de Letterer-Siwe) de evolución rápidamente fatal, que presentó una monocitosis de $2.300 \times \mathrm{mm}^{3}$, (con sólo $10 \%$ ), con monocitos y neutrofilos vacuolados. En la necropsia no se comprobó infección alguna. Además, 2 casos de enfermedad de Nieman-Pick en hermanos que presentaron en sus controles $10 \%$ de monocitos con 1.260 y 1.650

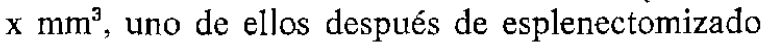
por hiperesplenia severa (el bazo pesó más de 1 kilo).

En la tabla No 4 se relaciona la intensidad de la monocitosis con la etiología del cuadro clínico que la produjo o el momento de su aparición. 47 de los 57 casos $(82,5 \%)$ tienen entre 1.000 y 4.000 monocitos $\times \mathrm{mm}^{3}$. No se observa ninguna variación significativa, salvo una mayor tendencia a las cifras bajas en los casos virales agudas y a las cifras altas en los bacterianos agudos, lo que está en relación a la leucopenia relativa de los primeros y a la leucocitosis de las segundas.

Destacan en este sentido 2 casos con menos de 1.000 monocitos $\mathrm{x} \mathrm{mm}^{3}$, que en sentido estricto deben ser excluidos de las monocitosis, ya que el promedio normal entre 1 mes y 2 años de edad es de 500 a 700 monocitos $x \mathrm{~mm}^{3}$, con un 
TABLA № 4

Monocitosis Absoluta Según Causa

\begin{tabular}{cccccr}
\hline Monocitos $\mathrm{x} \mathrm{mm}$ & $\begin{array}{c}\text { Inf. Virales } \\
\text { agudas }\end{array}$ & $\begin{array}{c}\text { Inf. Bacter. } \\
\text { aguda }\end{array}$ & Convalec. & Neos. & Totales \\
\hline$<1.000$ & 1 & - & 1 & - & 2 \\
1.000 a 1.999 & 10 & 5 & 6 & - & 23 \\
2.000 a 2.999 & 7 & 5 & - & - & 13 \\
3.000 a 3.999 & 6 & 3 & 1 & 1 & 8 \\
$>4.000$ & 3 & 4 & 3 & - & 16 \\
\hline Monocitos Vacuolados & 9 & & & & 1 \\
\hline
\end{tabular}

TABLA No 5

Leucocitos $\mathrm{x} \mathrm{mm}^{3} \mathrm{y}$ causa de monocitosis

\begin{tabular}{|c|c|c|c|c|c|c|}
\hline Leucocito & $\mathrm{s} \times \mathrm{mm}^{3}$ & I. Virales & I. Bacterianas ag. & Conval. & Neos. & Totales \\
\hline$<$ & 4.000 & 1 & $一$ & 1 & - & 2 \\
\hline 4. a & 7.999 & 9 & 2 & 3 & 2 & 16 \\
\hline 8. a & 11.999 & 10 & 4 & 3 & - & 17 \\
\hline 12. a & 17.999 & 5 & 5 & 3 & - & 13 \\
\hline$>$ & 18.000 & 2 & 4 & 2 & 1 & 9 \\
\hline
\end{tabular}

rango entre 50 y 1.000 . Uno de ellos correspondió a una bronconeumonía viral con 3.300 leucocitos y $18 \%$ de monocitos, y el otro a un convalesciente de sindrome hemolítico-urémico con 3.000 leucocitos y $16 \%$ de monocitos. Las monocitosis extremas - sobre $6.000 \times \mathrm{mm}^{3}$ - correspondieron a una sepsis a citrobacter, una neumonitis crónica, una leucemia monocítica y un sindrome hemolítico-urémico grave (falleció), los 3 últimos con más de 40.000 leucocitos $x \mathrm{~mm}^{3}$. De mayor interés nos parece la presencia de monocitos vacuolados en 9 de los 27 casos virales agudos $(33 \% \mathrm{x}), 4$ de $\operatorname{los} 15$ casos bacterianos agudos $(27 \%$ xx $)$ y 3 de los 12 convalescientes $(25 \% \mathrm{xxx})$. (x: 2 bronquiolitis obstructivas, 2 neumonitis $y$ una bronquitis, bronconeumonía, diarrea aguda y sindrome hemolítico-urémico respectivamente) ( $\mathrm{xx}: 3$ casos de sepsis y una bronconeumonía) (xxx: 2 neumonitis crónicas y una diarrea de evolución tórpida).

Queremos hacer resaltar aquí también la enorme variabilidad de los monocitos en los hemogramas hechos en fechas relativamente próximas en un mismo caso, y la necesidad de valorar más bien las cifras absolutas de monocitos. Así por ejemplo un caso de neumonitis aguda tiene al llegar al hospital $14 \%$ de monocitos $\left(2.702 \times \mathrm{mm}^{3}\right)$, pero ingresa al estudio 3 días después con $31 \%$ de monocitos (y sólo $1.674 \mathrm{x} \mathrm{m}^{3}$ ). Un caso de diarrea aguda tiene al ingreso $12 \%$ de monocitos $\left(3.264 \times \mathrm{mm}^{3}\right)$, siendo captada por el estudio 10 días después con $16 \%\left(3.322 \times \mathrm{mm}^{3}\right) ; 12$ días más tarde con $5 \%$ de monocitos, todavía tiene $1.980 \times \mathrm{mm}^{3}$, comprobándose una sepsis a Klebsiella con enterocolitis necrótica superficial y bronconeumonía bilateral en la necropsia. El mismo hecho se repitió en dos neumonitis que evolucionaron hacia la cronicidad. Una ingresó al hospital con $12 \%$ de monocitos $\left(1.753 \times \mathrm{mm}^{3}\right.$ ), un mes después de captada por nuestro estudio con $31 \%$ de monocitos $\left(6.944 \times \mathrm{mm}^{3}\right)$. La segunda ingresó con $10 \%$ de monocitos $(2.480 \mathrm{x}$ $\mathrm{mm}^{3}$ ), evolucionó durante un mes con cifras absolutas que alcanzaron a $5.544 \times \mathrm{mm}^{3}$ (sólo $11 \%$ ), y sólo fue captada por nosotros cuando en un reingreso al hospital 2 meses después presentó $21 \%$ de monocitos, pero con sólo $1.344 \times \mathrm{mm}^{3}$, Un caso de sindrome hemolítico-urémico ingresó con $16 \%$ de monocitos y sólo $480 \times \mathrm{mm}^{3}$, en cambio a los 7 días tenían con sólo $1 \%, 1.860 \mathrm{x} \mathrm{mm}^{3}$ Un caso de sarampión ingresó con $22 \%=2.604$ monocitos; 7 días después todavía tenía $22 \%$, pero sólo $990 \times \mathrm{mm}^{3}$. Finalmente una meningitis neumocócica con bronconeumonía ingresó con

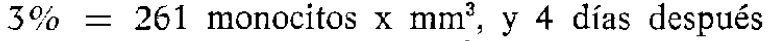
tenía $19 \%$ con $2.337 \mathrm{x} \mathrm{mm}^{3}$. Este último caso 
Neutrófilos $\mathbf{x} \mathbf{m m}^{3}$ y Causa de Monocitosis

\begin{tabular}{|c|c|c|c|c|c|c|c|}
\hline \multicolumn{3}{|c|}{ Neutrófilos $\times \mathbf{m m}^{3}$} & \multirow{2}{*}{$\frac{\text { I. Virales Ag. }}{-}$} & \multirow{2}{*}{$\frac{\text { I. Bact. Ag. }}{-}$} & \multirow{2}{*}{ Conval. } & \multirow{2}{*}{$\frac{\text { Neos. }}{-}$} & \multirow{2}{*}{$\frac{\text { Totales }}{-}$} \\
\hline & $<$ & 500 & & & & & \\
\hline$<500$ & - & 999 & 2 & - & 1 & - & 3 \\
\hline 1.000 & 一 & 3.799 & 15 & 5 & 5 & 2 & 27 \\
\hline 3.800 & - & 8.999 & 8 & 4 & 4 & 1 & 17 \\
\hline$>$ & & 9.000 & 2 & 6 & 2 & - & 10 \\
\hline
\end{tabular}

TABLA N: 7

Linfocitos $\mathrm{x} \mathrm{mm}^{3}$ y causa de monocitosis

\begin{tabular}{rrrrrrrr}
\hline \multicolumn{2}{l}{ Linfocitos } & $\mathbf{x ~ \text { mm} ^ { 3 }}$ & I. Viral Ag. & I. Bact. Ag. & Conval. & Neos. & Totales \\
\hline$<$ & 1.000 & - & - & - & 1 & 1 \\
1.000 & a & 2.499 & 7 & 4 & 2 & 1 & 14 \\
2.500 & a & 5.999 & 13 & 9 & 1 & 1 & 30 \\
6.000 & a & 12.999 & 6 & 1 & 1 & - & 9 \\
$>$ & 13.000 & 1 & 1 & & \\
\hline
\end{tabular}

es especialmente demostrativo de la enorme capacidad de respuesta de la médula en relación a la rápida entrega de monocitos, lo que ha sido demostrado experimentalmente en publicaciones muy recientes (11).

El caso extremo de monocitosis relativa fue de $55 \%$ en una sepsis a citrobacter en tratamiento, pero como tenía una leucopenia de 1.660 sólo alcanzó a 913 monocitos $\times \mathrm{mm}^{3}$.

En la tabla No 5 se relaciona la cifra total de leucocitos con la causa de la monocitosis. Se observa que sólo 2 casos tienen una neutropenia franca (una bronconeumonía viral y un convalesciente de sindrome hemolítico-urémico). Como era de esperar en las infecciones virales predominaron las cifras normales o bajas de leucocitos (20 de los 27 casos $=74 \%$ ), en tanto entre las infecciones bacterianas se acumulan los casos con leucocitosis moderada o franca ( 9 de 15 casos $=60 \%$ ). Sin embargo los casos extremos de leucocitosis correspondieron a cuadros virales: un sindrome hemolitico-urémico $\left(43.600 \mathrm{x} \mathrm{mm}^{3}\right)$ y una neumonitis crónica $\left(50.400 \mathrm{~mm}^{3}\right)$, seguidos por la leucemia monocítica $\left(43.000 \times \mathrm{mm}^{3}\right)$ y un caso de sepsis con $29.000 \times \mathrm{mm}^{3}$. El otro caso de convalesciente con leucocitosis franca corresponde a la segunda neumonitis crónica.

En la tabla No 6 se relaciona la cifra absoluta de neutrófilos con la causa que produjo la monocitosis. La neutropenia ( $<$ de $3.800 \times \mathrm{mm}^{3}$ ) se presentó de preferencia en las infecciones virales, correspondiendo la más severa (528 neutrófilos $\mathrm{x}$ $\mathrm{mm}^{3}$ ) a una bronconeumonía viral. Los otros 2 casos que bordean los 1.000 neutrófilos $\mathrm{x} \mathrm{mm}$ correspondieron a una bronquitis aguda y a un convalesciente de diarrea aguda. Las neutrofilias francas predominaron en las infecciones bacterianas agudas, acompañándose de alteraciones tóxicodegenerativas y/o desviación izquierda franca. 4 casos de sepsis bacterianas presentaron cifras entre 17.000 y $24.000 \mathrm{x} \mathrm{mm}^{3}$. Sin embargo entre los cuadros virales también se presentaron neutrofilias importantes, destacando un caso de sindrome hemolítico urémico fatal $\left(21.075 \times \mathrm{mm}^{3}\right)$, una neumonitis aguda. $\left(12.931 \mathrm{x} \mathrm{mm}^{3}\right)$, un sarampión $\left(8.060 \times \mathrm{mm}^{3}\right)$ y una neumonitis crónica con $19.152 \times \mathrm{mm}^{3}$; algunos incluso con desviaciones izquierda y alteraciones tóxicas moderadas, y el sindrome hemolítico-urémico con neutrófilos vacuolados.

En la tabla No 7 se relaciona la cifra absoluta de linfocitos con la causa de la monocitosis. 15 de los 57 casos $(26 \%)$, tienen una linfopenia franca, correspondiendo una proporción similar a las infecciones virales y bacterianas (土 $25 \%$ c/u.). Los casos extremos se presentaron en el

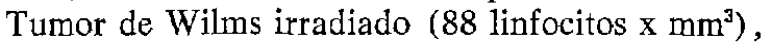
en la enfermedad de Hodgkin (1.008 $\mathrm{x} \mathrm{mm}$ ) y en el caso benigno de sindrome hemolítico urémico. La linfopenia acompañada de monocitosis no fue un índice de mal pronóstico en nuestro material. 30 casos $(52,6 \%)$ presentaron valores nor- 
TABLA No 8

Linfocitos Hiperbasófilos y/o monocitoides y Causa

de Monocitosis

\begin{tabular}{cccccc}
\hline \% Linfocitos Atípicos & Inf. Virales Ag. & Inf. Bact. Ag. & Convaleciente \\
\hline & & 0 & 1 & 12 & 2 \\
10 & 10 & 12 & 3 & 6 \\
& & 20 & 13 & - & 4 \\
\hline
\end{tabular}

TABLA N: 9

Eosinófilos $\mathrm{x} \mathrm{mm}^{3}$ y causa de Monocitosis

\begin{tabular}{rccccr}
\hline Eosinófilos $\mathbf{x}$ mm $^{3}$ & Inf. Virales Ag. & Inf. Bact. Ag. & Conval. & Neos. & Totales \\
\hline $0-40$ & 14 & 9 & 7 & 1 & 31 \\
$40-299$ & 8 & 5 & 1 & - & 14 \\
$300-799$ & 4 & 1 & 2 & 1 & 8 \\
$>800$ & 1 & - & 2 & 1 & 4 \\
\hline
\end{tabular}

TABLA № 10

Mortalidad en las Monocitosis

\begin{tabular}{|c|c|c|c|c|}
\hline $\mathbf{N}^{2}$ & Edad & $\begin{array}{l}\text { Monocitos } \\
\mathbf{x} \mathbf{m m}^{3}\end{array}$ & Diagnóstico & A. Patológica \\
\hline 1 & 21 dias & 1.501 & $\begin{array}{l}\text { Bronconeumonía Bilateral } \\
\text { Sepsis }\end{array}$ & No \\
\hline 2 & 4 meses & 1.755 & $\begin{array}{l}\text { Meningitis Hemophilus } \\
\text { Sepsis }\end{array}$ & Sí \\
\hline 3 & $51 / 2 \mathrm{~ms}$. & 3.332 & $\begin{array}{l}\text { Enterocolitis } \\
\text { Bronconeumonía Bilateral } \\
\text { Sepsis (Klebsiella) }\end{array}$ & Sí \\
\hline 4 & $61 / 2 \mathrm{~ms}$. & 1.683 & $\begin{array}{l}\text { Bronconeumonía difusa } \\
\text { Sepsis (Proteus) } \\
\text { Cardiopatía congénita }\end{array}$ & Sí \\
\hline 5 & $71 / 2 \mathrm{~ms}$. & 11.336 & $\begin{array}{l}\text { Sindrome hemolítico-urémico } \\
\text { Necrosis cortical bilateral } \\
\text { Insuficiencia renal aguda }\end{array}$ & Sí \\
\hline 6 & 1 a $11 \mathrm{~ms}$. & 1.892 & $\begin{array}{l}\text { Enterocolitis grave } \\
\text { ¿Sepsis? }\end{array}$ & No \\
\hline 7 & 2 a $6 \mathrm{~ms}$ & 1.056 & $\begin{array}{l}\text { Sepsis viral con: Neumonitis, } \\
\text { Miocarditis y Encefalitis }\end{array}$ & Sí \\
\hline
\end{tabular}

males de linfocitos. La linfocitosis moderada (entre el promedio y el rango normal alto) predominó en las infecciones virales. Linfocitosis franca presentaron sólo 3 casos: un sindrome hemolítico urémico $\left(14.400 \times \mathrm{mm}^{3}\right)$, una sepsis bacteriana a Klebsiella (14.994 $\times \mathrm{mm}^{3}$ ) (ambos fallecieron) y una neumonitis crónica $\left(23.688 \times \mathrm{mm}^{3}\right)$ que evo- lucionaba con insuficiencia respiratoria importante. En nuestra casuística la linfocitosis extrema asociada a monocitosis significó un muy mal pronóstico.

En la tabla № 8 se relaciona la causa de la monocitosis con la presencia en el Hemograma de linfocitos "atípicos". Se destaca que su fre- 
cuencia e intensidad tiene una clara relación con las infecciones virales agudas, es poco significativa en las infecciones bacterianas agudas, persistiendo o apareciendo nuevamente en la convalecencia tanto de infecciones virales como bacterianas. Debemos señalar que en este último grupo, 2 de los 4 casos con más de 10\% de "linfocitos atípicos" correspondieron a las neumonitis interticiales crónicas que presentaban todavía monocitos vacuolados a los 2 ó 3 meses del inicio de su enfermedad, to que hace suponer que se trataba de una infección viral persistente.

En la tabla No 9 se analiza el comportamiento de los eosinófilos en los casos de monocitosis. En la gran mayoría ( 45 de $57=79 \%$ ) los eosinófilos estaban ausentes o en el rango normal bajo. Sólo 4 presentaron eosinofilia definida aunque no muy alta $\left(880\right.$ a $\left.2.016 \times \mathrm{mm}^{3}\right)$, correspondiendo la cifra más alta a una neumonitis interticial crónica.

En la tabla No 10 se resumen los 7 casos fallecidos de un total de 53 menores de 3 años, lo que constituye el 13,3\%. En 5 de ellos el diagnóstico se comprobó mediante el estudio anátomopatológico. Ninguno presentó leucopenia importante. 2 presentaron leucocitosis (los N.os 3 y 5 ) de 23.800 y $43.600 \times \mathrm{mm}^{3}$, con linfocitosis de 14.994 y $14.440 \times \mathrm{mm}^{3}$, respectivamente. Son los únicos que tenían además cifras altas de monocitos, correspondiendo el record absoluto al sindrome hemolítico-urémico, con 11.336 monocitos $\mathrm{x} \mathrm{mm}$. De los 4 casos mayores de 3 años, 3 correspondieron a neoplasias y de ellos 2 fallecieron ( $\mathrm{T}$. de Wilms y leucemia monocítica) .

En la tabla No 11 se detallan todas las causas de monocitosis detectadas en nuestro material. Predominan ampliamente las infecciones respiratorias, lo que puede deberse en gran parte a que el estudio se realizó entre otoño y primavera, no incluyendo los meses estivales en que aumenta la frecuencia de las infecciones enterales. Sin embargo pensamos que también contribuyen las características inmunológicas especiales del lactante pequeño (déficit de $\operatorname{Ig}$ A secretoria) y el hecho que el pulmón sea un órgano que acumula una importante proporción de macrófagos. Nos llama la atención no encontrar ningún caso de infección por Listeria monocitógena, pese a incluir lactantes pequeños y tener nuestro Hospital una Maternidad, que atiende alrededor de 9.000 partos anuales, con una unidad de Recién Nacido anexa que recibe todos los prematuros y recién nacidos con patología

\section{DISCUSION:}

Nos parece de interés comentar 3 aspectos en relación a los monocitos: $1^{\text {? }}$ su origen, quinética y rol en las defensas del organismo; $2^{\circ}$ el papel que juega en las infecciones y neoplasias y $3^{\circ}$ su importancia en la primera infancia.

1.- El monocito se origina en la médula después de 2 ciclos mitóticos del promonocito, lo que sucede normalmente en 58 hrs., entregándose 4 monocitos maduros a la circulación. Bajo un estímulo inflamatorio se acelera este proceso, dando en el mismo tiempo 4 ciclos mitóticos con entrega de 16 monocitos con menor grado de maduración (núcleo redondo u ovalado). Se puede así en $21 / 2$ días duplicar la producción de monocitos (12). En la sangre circula normalmente entre 22 y 32 hrs. (vida media), pasando de acuerdo a las necesidades a los tejidos o serosas donde se transforma en histiocito macrófago (13). Sin embargo se ha visto experimentalmente que al producirse una infección por salmonella, por ej.) hay una rápida caída paralela de leucocitos y monocitos en el primer día (marginación y consumo), recobrándose ya al 3er. día el valor inicial, para alcanzar al $4^{\circ}$ día una cifra 2,5 veces superior al valor inicial que persiste hasta el $10^{\circ}$ día sin variación importante (14). Los macrófagos que se acumulan en los sitios de inflamación derivan del monocito circulante. Hay en este proceso una estrecha interrelación funcional con los linfocitos tanto $\mathrm{B}$ como $\mathrm{T}$, que producen substancias llamadas linfoquinas que estimulan la producción y luego atraen al monocito al sitio inflamatorio, lo inmovilizan y activan en sus funciones fagocíticas y bactericidas (para una revisión más completa véase referencias 15 y 5). En este proceso también juegan un rol importante los anticuerpos citofílicos y las opsoninas (Igs y complemento). Publicaciones muy recientes (1972-1974) enfatizan todavía que el rol exacto del monocito debe ser establecido (16) y que se sabe poco de su comportamiento cuando hay demanda aumentada y de qué modo se realiza este proceso (14). Sin embargo en la década del 60 y especialmente de 1970 en adelante se ha trabajado intensamente para aclarar estos aspectos.

2.- Se ha establecido así que el monocito macrófago juega un rol preponderante en la defensa frente a organismos intracelulares (virus, bacilo TBC, Salmonella, listeria, Brucella y parásitos del tipo del Toxoplasma, etc.) y en relación a neoplasias (ver revisión en 5). Destacaremos aquí especialmente su importancia en las infecciones virales, ya que éstas fueron la causa más frecuente de mo- 
TABLA No 11

Lista General de Causas de Monocitosis en Pediatría

1.- Infecciones Virales Agudas:

a) Respiratorias: Bronquitis 8

Bronconeumonías 6

Neumonitis 3

Bronquiolitis 2

Sarampion $\quad 1$

Gripe 1

Sepsis viral 1

(Neumonitis +

Miocarditis +

Encefalitis)

b) Enterales: Enteritis 4

Sindrome Hemolítico-urémico 1

2.- Infecciones Bacterianas Agudas:

Sepsis bacterianas

(+ Bronconeumonía 5

+ Meningitis 1)

- Citrobacter 2

- Estafilococo 1

- Hemophilus 1

- Klebsiella 1

- Proteus 1

Enterocolitis 3

Bronconeumonía 3

Meningitis (Hemophilus) 1

3.- Convalecientes (de Inf. Agudas)

a) Infecciones enterales

Enterocolitis 4

Sepsis (pseudomona) 1

Sindrome Hemolítico-urémico 1

Tifoidea prolongada

1

b) Infecciones respiratorias

5

Neumonitis crónica 2

Bronconeumonía 1

Meningitis Neumocócica 1

Sindrome de Reyé 1

4.- Neoplasias

Tumor de Wilms $(+\mathrm{Rx}) \quad 1$

Hodgkin IV 1

Leucemia monocítica 1

5.- Misceláneas

3

(Nieman-Pick 
nocitosis en nuestro material. Frente a ellos, la primera barrera del organismo la constituyen los anticuerpos del tipo IgA secretoria que neutralizan al virus agresor en la superficie mucosa (respiratoria, digestiva, etc.), o sea, fuera del organismo. Vencida esta barrera, se encuentra el invasor con las opsoninas plasmáticas (anticuerpos del tipo Ig G $\mathrm{y} / \mathrm{o}$ Ig $\mathrm{M}$ y el complemento) que inactivan al virus y facilitan su fagocitosis y destrucción final. Si no existe esta segunda barrera el virus puede ser destruido en el interior de los macrófagos por la activación de estos vía linfocito $\mathrm{T}$ y $\mathrm{B}$, los que producen $\mathrm{e}$ inducen la producción de interferon en el macrófago, substancia que impide la multiplicación viral (17-18). Siendo muy importante la inmunidad humoral y secretoria, en la resistencia a muchos virus no hay participación de anticuerpos, dependiendo en última instancia la erradicación de la infección de la inmunidad celular. En relación al virus vacinal, por ej., basta la producción de interferón para inhibir la infección (19). Es así el macrófago, efector final tanto de la inmunidad "humoral" como "celular", con su enorme poder bactericida (enzimos líticos) y productor de interferón, quien resuelve el problema. En esta función el macrófago puede sobrevivir (a diferencia del polimorfonuclear neutrófilo), pero a veces queda profundamente afectado por virus citopatogénicos como los de sarampión, varicela, poliomielitis, etc. A ello se debe la anergia postinfecciosa que dura alrededor de 3 semanas $(20,21)$. Frente a infecciones bacterianas el problema es similar, participando en unas preferentemente el linfocito B - anticuerpos y macrófagos (Salmonella, Brucella ...) y en otras casi exclusivamente el linfocito $\mathrm{T}$ y el macrófago (TBC, Listeria). Esta dicotomía también es válida en relación a neoplasias $(22,23,24)$. Creemos pertinente acotar aquí que los monocitos producen un pirógeno diferente del de los neutrófilos, que aparece a las 4 hrs. y persiste durante 36 hrs. y que es responsable de la temperatura alta y monofásica que se observa en la agranulocitosis, leucemia monocítica y enfermedad de Hodgkin (25).

3.- Los monocitos se detectan en la sangre a partir de la octava semana de gestación. Entre las 10 semanas y el término varían entre 0 y $1.000 \times \mathrm{mm}^{3}$. En el recién nacido — sangre del cordón- se encuentran entre 200 y 1.600 monocitos $\times \mathrm{mm}^{3}$, cifra que sube en las primeras $12 \mathrm{hrs}$. a $400-3.100 \times \mathrm{mm}^{3}$ (promedio 1.050$)$, permaneciendo en valores altos (300 a $\left.2.500 \times \mathrm{mm}^{3}\right)$ durante las 3 semanas siguientes $(26,27)$. En los primeros 2 años el promedio se mantiene entre 700 (1 mes) y 500 (2 años), con un rango que fluctúa entre 50 y $1.000 \times \mathrm{mm}^{3}$ (7). Recién a los 4 años se alcanzan los niveles del adulto, (26) o sea menos de 500 mono-

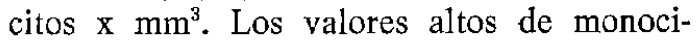
tos en la primera infancia deben traducir un ajuste funcional que implica una mayor actividad del sistema mononuclear fagocitario. En nuestro trabajo elegimos la cifra de 1.000 monocitos $\times \mathrm{mm}^{3}$ como la cifra máxima normal para niños de 1 mes a 2 años de vida, y de 800 para los mayores. En la casuística presentada el $90 \%$ de las monocitosis se presentaron en el primer año de vida, especialmente en los primeros 6 meses. Creemos que esto debe atribuirse a las características inmunológicas del lactante pequeño. El recién nacido tiene una inmunidad celular activa, pero una relativa ineficiencia de las células procesadoras de antígenos, que puede corregirse con macrófagos adultos (27). La madre le ha traspasado anticuerpos de la fracción $\mathrm{Ig} G$, pero carece de un eficiente poder opsónico (falta Ig M y deficiente C) que puede restituirse con plasma de adulto, y que alcanza en general los niveles normales entre los 3 y 6 meses (29). Carece además de inmunoglobulina secretoria ( $\mathrm{Ig} \mathrm{A}$ ), recibiendo en este sentido protección a nivel del tubo digestivo junto con la leche materna. En estas condiciones su punto más vulnerable es la mucosa respiratoria. Se explica así la mayor incidencia de infecciones respiratorias tanto virales como bacterianas, $y$ en aquellos que no reciben leche materna, también de infecciones digestivas.

En los meses siguientes al nacimiento disminuyen gradualmente las Ig G maternas, llegándose al 3er. mes a la hipogamaglobulinemia fisiológica. El lactante depende ahora casi en todo a su propia capacidad de defensa. No disponiendo de anticuerpos, debe sintetizarlos gradualmente y ello solicita la participación de sistema linfocito B- monocito-macrófago, y exige también una mayor actividad de la inmunidad celular, o sea del sistema linfocito T- monocito-macrófago. Pueden explicarse así la monocitosis que se presentan en el curso de infecciones virales y bacterianas, y que estas infecciones sean más frecuentes y graves que en edades posteriores. Es significativo que en nuestra casuística disminuyen francamente los monocitos a los 6 meses y prácticamente desaparecen al año 
de vida. Vale la pena recordar aquí la importancia del brazo en el primer año. Este órgano está constituido por un acúmulo importante de macrófagos y linfocitos, y por su disposición anátomo-funcional de filtro sanguíneo es capaz de cumplir su función fagocitaria con bajo poder opsónico. Al año de vida todavía entre el 15 y $20 \%$ de los niños no tienen $\operatorname{Ig} M$ sérica detectable con actividad frente a gérmenes patógenos como estafilo y neumococo, hemophilus y bacterias entéricas. Esta falta de opsoninas específicas los hace especialmente vulnerables a bacterias capsulados como neumococo y hemophilus (30) y a enteropatógenos. Fue precisamente este grupo de bacterias las que produjeron las infecciones más serias en nuestra casuística (10 sepsis y 3 meningitis) .

Después de los 3 años cambia el tipo de patología que solicita el trabajo del sistema mononuclear fagocitario. Empiezan a predominar las neoplasias y casi desaparecen los procesos infecciosos, que son ya más de tipo sub-agudo o crónico. Esto no se diferencia en nada de las monocitosis del adulto (31).

\section{RESUMEN :}

Entre marzo y noviembre de 1974 reunimos y estudiamos 57 niños hospitalizados que tuvieron más de $15 \%$ de monocitos en el Hemograma.

51 casos (90\%) eran lactantes menores de 1 año. La distribución nosológica reveló 28 infecciones respiratorias, 11 infecciones enterales, 10 sepsis bacterianas, 3 meningitis, 2 sindrome hemolitico-urémicos, un sindrome de Reyé y 3 neoplasias.

27 casos ( $47 \%$ ) fueron catalogados como infecciones virales agudas ( 22 de tipo respiratorio). 15 casos (26\%) correspondieron a infecciones bacterianas agudas y 12 casos (21\%) a convalecientes de los mismos cuadros que determinaron las monocitosis agudas.

Se analizan en detalle las cifras absolutas de leucocitos y la presencia y significado de monocitos vacuolados. Se destaca como de mal pronóstico la monocitosis asociada a linfocitosis importante. 7 de 53 casos menores de 3 años fallecieron, comprobándose en 5 el diagnóstico en anatomía patológica.

Se discute el origen, quinética y rol del monocito en las defensas del organismo; su estrecha interrelación funcional con los linfocitos $T$ y $B$; el papel que desempeña en las infecciones virales o bacterianas y su importancia fundamental en el primer año de vida.

\section{REFERE N C I A S}

1.- Barnett, H. L.: Pediatrics, 14 Ed., pag. 1165, Appleton-Century-Crofts. New York, 1968.

2.- Nelson, W. E.: Texbook of Pediatrics, 10th. Ed. pag. 1139; W. B. Saunders Co., Philadelphía, 1975.

3.- Cooke, R. E.: The Biologic Basis of Pediatrics Practice. Pag. 455-457; Mc. Graw-Hill, New York 1968.

4.- Smirh, C. H.: Blood Diseases of Infancy and Childhood, 3 th. Ed. Pag. 489; M. V. Mosby Co., Saint Louis; 1972.

5.- Taboada, H.: El Sistema Mononuclear Fagocitario, Rev. Chile Pediat. (en prensa).

6.-Zucker-Franklin, D.: The porcentage of monocytes among "mononuclear" cell fractions obtained from normal human blood. J. Immunol. 112: 234, 1974.

7.- Derman, H.: Hematological Normas in Infancy, pag. 376 - The Clinical Pathology of Infancy Charles C. Thomas, 1967.

8.-Wetxel, R.: "Ueber "milienbedingte" Monocytosen. Ztsch. Klin. Med. 146: 134, 1950.

9.-Lieberman, E.: Hemolyticuremic syndrome. J Pediat 80: 1, 1972

10.- Linneman, C. C. $\mathbf{y}$ col.: Association of Reye's syndrome with viral infection. Lancet 2: 179, 1974.

11.- Van Furth, R. y col.: Quantitative study on the production and kinetics of mononuclear fagocites during an acute inflamatory reaction. J. Exp. Med. 138: 1314, 1973.

12.-Meuret, G. y col.: Kinetics of human monocytopoieses. Blood 44: 801, 1974.

13.-Van Furth, R.: Origen and Kinetics of monocytes and macrophages. Seminars Hemat. 7: 125, 1970.

14.- Volkman, A., Collins, F. M.: The cytokinetics of monocytosis in acute Salmonella infection in the rat. J. Exp. Med. 139: 264, 1974.

15.-Fedorko, M. E. y otros: Symposius sobre monocitos y macrófagos. Seminars Hematol. 7: 1-225, 1970. 
16.-Murdock, I. Mc. C., Smith, C. C.: Infection, Clinics. Haemat. 1: 619, 1972.

17.- Silvestein, S.: Macrophages and viral inmunity. Seminars Hemat. 7: 185, 1970.

18.- Mims, C. A.: Aspects of the pathogenesis of virus diseases. Bact. Rev. 28: 30, 1964.

19.- Friedman, R. M. y col.: The role of antibody, delayed ippersensivity and interferon production in recovery from primary infection with vaccinia virus. J. Exp. Med. 116: 347, 1962.

20.- Twomey, J. J. y col.: The monocytc disorder with herpes zoster. J. Lab. Clin. Med. 83: 768, 1974.

21.- Soutiens, J. T., Van de Veen ,J.: Evidence for a macrophage-mediated efect of poliovirus on the lymphocyte response to phytohemaglutinin. I. Immunol. 111: 1411, 1973.

22.- Piessens, W. F. y col.: Macrophages activated in vitro with lymphocyte mediators kill neoplastic but not normal cells. J. Immunol. 144; 293, 1975.

23.- Evans, R., Alexander, P.: Rol of macrophages in tumor immunity. Immunol. 23: 615, 1972.
24.-Evans, R., Alexander, P.: Involvement of macrophage cytophylic factor during singeneic tumor growth inhibition. Immunol. 23: 627, 1972.

25.- Bodel, P.: Studies on the mechanism of endogenous pyrogen production by human blood monocytes. J. Exp. Med. 140: 954, 1974.

26.-Black, P. J., Barkhan, P.: The blood and bonemarrow during growth and development, p. 323 de Scientific Foundation of Pediatrics, W. B. Saunders Co. Philadelphia, 1974.

27.-Oski, F. A., Naiman, J. L.: Hematologic problems in the Newborn; pag. 4 y 14, W. B. Saunders Co. Philadelphia, 1966.

28.- Argyuris, B. F.: Role of the macrophages in immunological maturation. J. Exp. Med. 128: 459, 1968.

29.- Fireman, P. y col.: Development of human complement system. J. Immun. 103: 25, 1969.

30.-Lynch, M. J.: Mechanism and defects of the phagocytic system of defense against infection. Perspectives in Pediatric Pathology 1: 93, 1973.

31.-Maldonado, J. E., Hanlon, D. G.: Monocytosis: a current apraisal. Mayo Clin. Proc. 40: 248, 1965. 